\title{
Dermatomiositis paraneoplásica: a propósito de dos casos.
}

\author{
Paraneoplastic dermatomyositis: report of two cases
}

\author{
Pedrosa Fraga C1ㄴ Taboada Rivas S², García Trincado B¹, Piñeiro Fernández JC1 \\ ${ }^{1}$ Servicio de Medicina Interna. Hospital Universitario Lucus Augusti. Lugo. SERGAS. ${ }^{2}$ Centro de salud de Xermade, Lugo. SERGAS
}

\section{RESUMEN:}

La dermatomiositis es una miopatía inflamatoria con una incidencia de 0.5-1 caso por 100.000 habitantes. Se caracteriza por lesiones cutáneas típicas y debilidad muscular, aunque ocasionalmente podemos encontrar formas amiopáticas. La asociación con malignidad ha sido ampliamente descrita en la literatura, habiéndose detectado tumores hasta en un tercio de los casos. La presencia del anticuerpo anti-TIF-1-gamma presenta tasas más altas de neoplasia comparada con otras formas sin este anticuerpo, lo que obliga a realizar un despistaje tumoral. A continuación, presentamos 2 casos de dermatomiositis asociada a anticuerpo TIF-1-gamma asociadas a malignidad.

\section{INTRODUCCIÓN}

La dermatomiositis es una enfermedad autoinmune sistémica que se engloba dentro de las miopatías inflamatorias idiopáticas. Es una entidad bien diferenciada dentro de este grupo, ya que presenta unas lesiones cutáneas y unos hallazgos histológicos musculares característicos. Aunque en su mayor parte se asocia a miopatía, existen formas amiopáticas o hipomiopáticas. Se considera una enfermedad multisistémica donde, además de la afectación cutánea y muscular, podemos encontrar afectación pulmonar, cardíaca, articular o digestiva. Su incidencia es de 5-10 casos por 1 millón de habitantes y año, existiendo un predominio de mujeres ${ }^{1}$. Estudios epidemiológicos han demostrado un riesgo incrementado de neoplasia en estos pacientes, detectándose hasta en un tercio de los casos ${ }^{1}$. A continuación, presentamos dos casos de dermatomiositis paraneoplásica asociadas a autoanticuerpos anti-TIF1-gamma con diferentes espectros clínicos de la enfermedad.

\section{CASO CLÍNICO 1}

Varón de 65 años, exfumador e hipertenso, a tratamiento con olmesartán/amlodipino/hidroclorotiazida. Acudió a urgencias por mialgias generalizadas y debilidad progresiva de cintura pélvicaescapular de un mes de evolución. Presentaba lesiones cutáneas pruriginosas (abdomen inferior, nalgas, escote y párpados) y refería dolor epigástrico (cólico, leve, postprandial y autolimitado), de un año de evolución, asociado a anorexia. En la exploración física destacaban las lesiones cutáneas [eritemato-violáceas en nalgas, escote (signo de la V, Imagen 1) y párpados (eritema heliotropo)] y la exploración neurológica (fuerza 4/5 para la supraelevaciónabducción de hombros y 3/5 para la abducción-aducción de la cadera). El resto era normal. En el análisis inicial destacaban una creatina-fosfocinasa (CPK) de $8088 \mathrm{U} / \mathrm{L}$ y una aldolasa de 57.8 $\mathrm{U} / \mathrm{L}$. Ante la sospecha clínica de dermatomiositis se solicitaron: un estudio de autoinmunidad, detectándose anticuerpos antinucleares (ANA) 1/320 patrón moteado, con anti-Ro 52 y anti-TIF1-gamma positivos; y un electromiograma, que mostraba signos de miopatía en cintura pélvica y escapular. Además, se realizó un despistaje de neoplasia con una tomografía axial computarizada (TAC) toracoabdomino-pélvica y una gastroscopia, siendo diagnosticado de una

\begin{abstract}
Dermatomyositis is an inflammatory myopathy with an incidence of 0.5-1 case per 100,000 inhabitants. It is characterized by hallmark cutaneus findings and muscle weakness, although we can occasionally find amyopathic forms. The association with malignancy has been widely described in the literature, as tumors have been detected in up to a third of the cases. The presence of the anti-TIF-1-gamma antibody presents higher rates of neoplasia compared to other forms without this antibody, so it is mandatory to do a tumor screening. Next, we present 2 cases of TIF-1-gamma antibody-associated dermatomyositis associated with malignancy.
\end{abstract}

Keywords: Adult Type Inflammatory Myopathies; Dermatomyositis; Paraneoplastic Syndromes; TIF1gamma protein, human.

neoplasia gástrica cuya biopsia fue compatible con un adenocarcinoma de patrón mixto con afectación metastásica ganglionar.

En cuanto al tratamiento de la dermatomiositis, el paciente fue tratado con prednisona a dosis de $0.5 \mathrm{mg} / \mathrm{kg}$ con muy buena respuesta inicial, pero a los 10 días presentó un deterioro muscular grave, por lo que se iniciaron inmunoglobulinas y bolus de $250 \mathrm{mg}$ de metilprednisolona durante 3 días. El paciente fue trasladado a Oncología para iniciar quimioterapia, donde finalmente falleció tras un mes de ingreso.

\section{CASO CLÍNICO 2}

Mujer de 45 años con hipotiroidismo primario autoinmune a tratamiento con levotiroxina $50 \mathrm{mcg}$. Remitida a nuestra consulta por edema y eritema palpebral pruriginoso y fotosensible de 5 meses de evolución, refractario a antihistamínicos y glucocorticoides (tópico y sistémicos -prednisona $30 \mathrm{mg} /$ día-). Refería xerostomía, xeroftalmia y fenómeno de Raynaud bilateral en el $5^{\circ}$ dedo de ambas manos. No refería debilidad muscular ni otra clínica acompañante a la anamnesis dirigida. En la exploración física destacaban el eritema y edema difusos peri-palpebrales (Imagen 2), que se extendían hacia la región malar bilateral, y una placa violácea, ligeramente infiltrada, en la cara externa de ambos muslos (Imagen 3). El resto de la exploración era normal. Fue valorada por alergología, que descartó un edema angioneurótico (C1q inhibidor negativo), y por dermatología, que realizó biopsias del muslo izquierdo y el eritema palpebral, resultando ambas compatibles con una dermatomiositis. Se completó el estudio analítico objetivándose ANA 1/640 patrón moteado, con anti-Ro52 y anti-TIF1-gamma positivos, el resto fue normal. Se solicitaron unas pruebas de función respiratoria, mamografía, ecocardiograma y TAC toraco-abdomino-pélvica, que fueron normales. Se realizó también una exploración ginecológica, donde se demostró una formación morular y metaplasia tubárica (lesiones premalignas), por lo que se decidió realizar una histerectomía total con salpinguectomía bilateral y conservación de ovarios.

Fue diagnosticada de una dermatomiositis amiopática con manifestación preneoplásica asociada, iniciándose bolus de metilprednisolona de 125 mg (transición a prednisona oral en pauta descendente 
hasta $2.5 \mathrm{mg} /$ día de mantenimiento), hidroxicloroquina $200 \mathrm{mg} /$ día y metotrexato (máximo de $12.5 \mathrm{mg} / \mathrm{semana}$ ), con muy buena evolución y resolución de las lesiones cutáneas a los 6 meses de seguimiento.

\section{DISCUSIÓN}

La dermatomiositis es una enfermedad multisistémica que requiere un alto grado de sospecha y un seguimiento estrecho, por su riesgo de gravedad en asociación a neoplasias ${ }^{2}$ y pudiendo formar parte de síndromes overlap con otras enfermedades autoinmunes. Exponemos dos casos clínicos que representan la complejidad de esta enfermedad, con una evolución, tratamiento y pronóstico diferentes, ambos asociados a neoplasias y uno de ellos probablemente a otra enfermedad autoinmune.

La dermatomiositis tiene un amplio espectro clínico. Aunque en la mayoría de los pacientes existe debilidad muscular, existen formas hipomiopáticas o amiopáticas (caso 2). En las formas miopáticas la afectación característica es de la musculatura proximal, con debilidad de cinturas (caso 1)3. Presentan lesiones cutáneas características, la mayoría de ellas con un componente de fotosensibilidad que les confiere una localización típica. Existen dos lesiones patognomónicas: las pápulas de Gottron (erupción simétrica, descamativa e infiltrada de predominio en la superficie extensora de las articulaciones metacarpofalángicas e interfalángicas) y el eritema heliotropo (lesiones eritematosas en ambos párpados superiores que se suelen acompañar de edema palpebral), este último presente en ambos casos ${ }^{3}$. Otras lesiones características son el signo de la $\checkmark$ (eritema en la parte superior y anterior del tórax), el signo del chal (eritema en la región cervical baja), y menos frecuente, el signo de las pistoleras (eritema violáceo en cara lateral de muslos), como en el caso 2.

Las formas amiopáticas no suelen caracterizarse por un anticuerpo específico, pero pueden presentar varios anticuerpos clásicos de la enfermedad que van a ser más determinantes en el pronóstico que el propio hecho de tratarse de una forma amiopática ${ }^{4}$. Las lesiones cutáneas son las mismas que en las formas miopáticas.

A nivel analítico es frecuente observar elevación de enzimas musculares, siendo la CPK la más sensible ${ }^{5}$. Refleja la existencia de lesión muscular y ayuda al diagnóstico diferencial con otros trastornos que cursan con atrofia muscular. Se estima que suele estar elevada unas 10 veces sobre su valor normal (39-308 U/L de referencia en nuestro hospital), como en el caso 1. Sin embargo, en dermatomiositis amiopáticas o en fases iniciales cuando solo existen lesiones cutáneas, la CPK puede ser normal (caso 2). Otras enzimas que podemos encontrar elevadas son la ALT, AST, LDH, aldolasa, o mioglobina ${ }^{6}$.

Otro estudio diagnóstico es la electromiografía, aunque los hallazgos tienen baja sensibilidad y especificidad en relación con otros trastornos neuromusculares. Frecuentemente se observan actividad espontánea aumentada, fibrilaciones, ondas positivas, descargas miotónicas o complejos de descargas repetitivas ${ }^{6}$.

La alta prevalencia (entre un 60-80\%) de anticuerpos frente a antígenos intracelulares muestra el trasfondo autoinmune de esta enfermedad. El perfil de anticuerpos va a orientarnos a la afectación sistémica predominante ${ }^{7}$. Mientras que la presencia de anticuerpos antisintetasa (anti-J01, anti-PL7, anti PL12) va a dar lugar a un síndrome clínico con afectación articular, pulmonar y muscular, el anticuerpo anti-MDA5 se asocia con neumopatías intersticiales rápidamente progresivas y formas amiopáticas ${ }^{7}$. En
Fig.1. Vista del escote

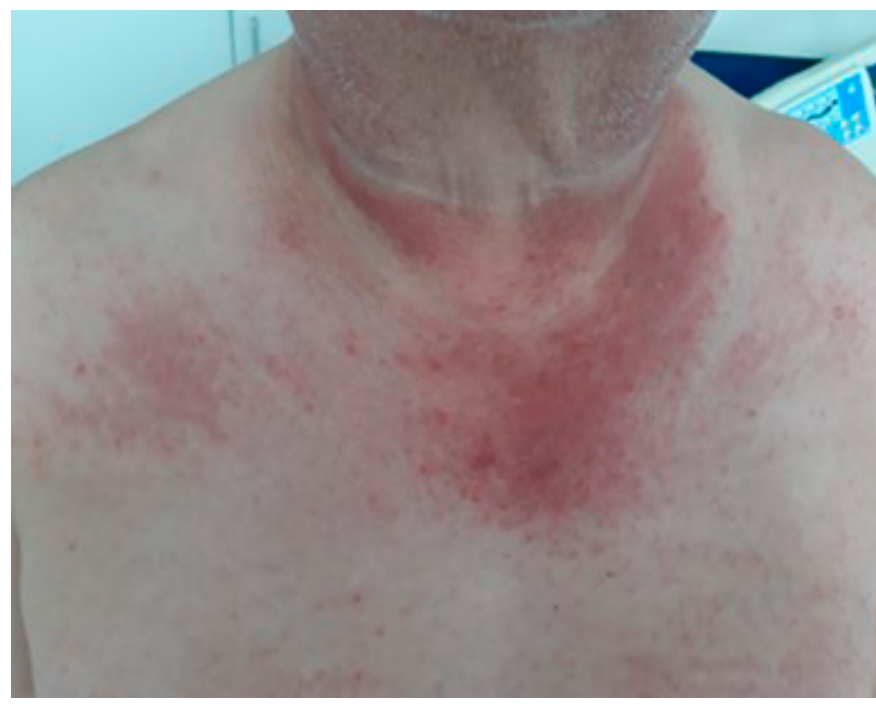

Fig.2. Eritema heliotropo

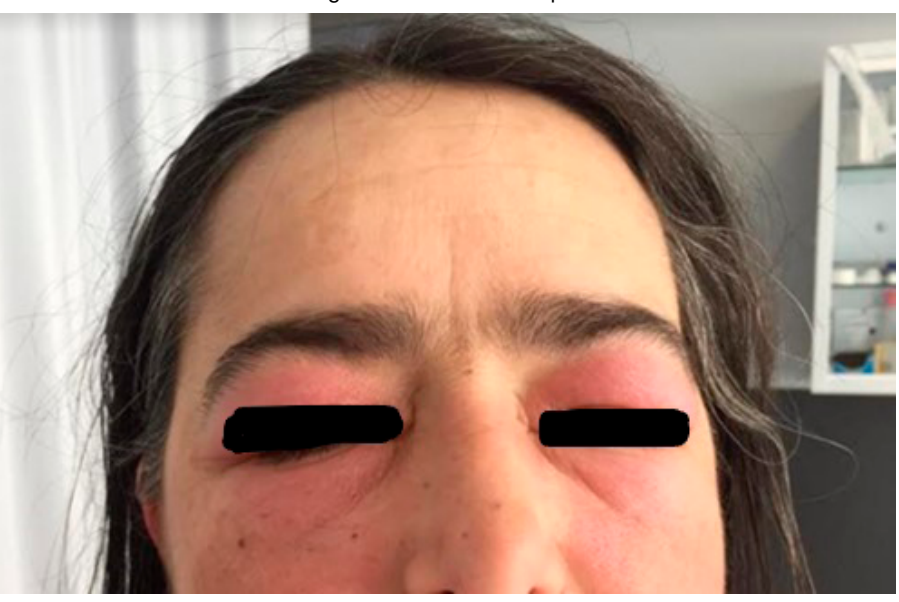

Fig.3. Signo de la pistoleras

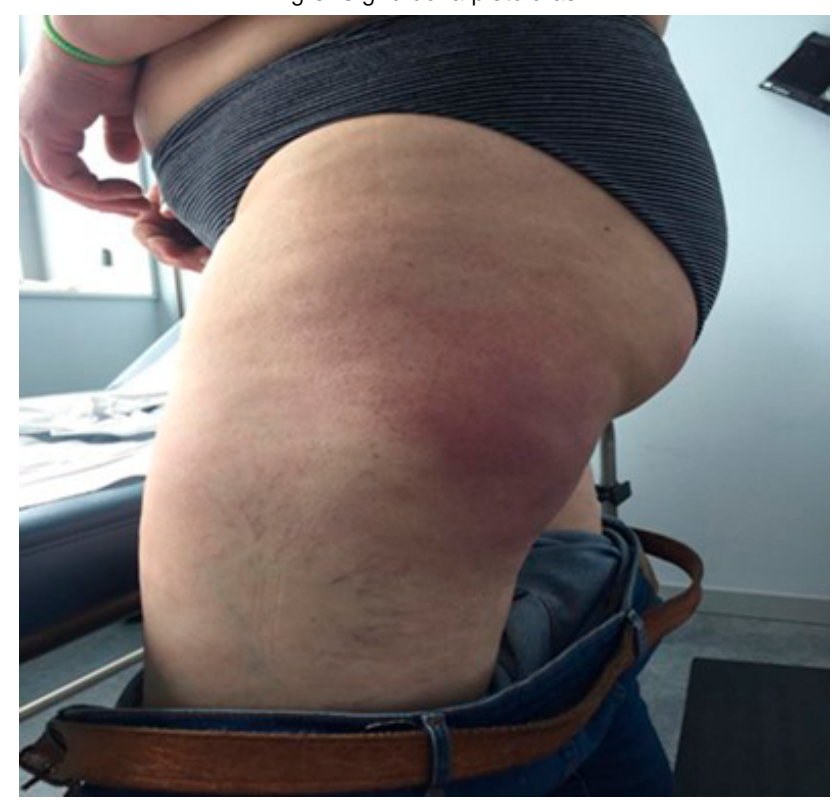

